\title{
Index of the Cycle of Money - the Case of Bulgaria
}

Received: 11.02 .2021

Available online: 28.06 .2021

\section{Constantinos Challoumis}

\section{Abstract}

This paper seeks to make clear how the concept of the cycle of money works in an actual case scenario like this of the economic system of Bulgaria. The index of the cycle of money suggests how an economic system ought to counteract a monetary crisis and examines how well-structured a country's economy is. The estimations of the index of the cycle of money of Bulgaria are compared with the global average index of the cycle of money. The estimations reveal that Bulgaria is close to the average global value. Bulgaria's results show that it is a well-structured economy and can face an economic crisis. The applied methodology stands on the analysis of the theory, mathematical, statistical, and econometrical results. The current work is important as it represents the strength of Bulgaria's economy to a potential crisis. The results could be achieved by the application of the theory of the cycle of money to a country's economy. Prior real case scenario conclusions are from Latvia.

Keywords: the cycle of money; Bulgaria, index of the cycle of money

JEL: C 58, F 39, H 80

\section{INTRODUCTION}

This paper examines the dynamic of the economy of Bulgaria, using the concept of the cycle of money. The theoretical background of the cycle of money supports that the dynamic of an economy is based on the idea of the number of times that money is used in an economy. An economy should be considered not as a closed system, but as a system with fragments. An economy with fragments means that the economy interacts with other economies but simultaneously protects its money. An amount of money in many cases gets out from an economy to external banks, or other economies. The mainstream is that the bigger companies and the international companies in most cases save their money to external banks and economic heavens. Therefore, according to this theory, the tax authorities should put an additional tax on this kind of companies to reduce the losses to the economy. Moreover, the smaller companies and the freelancers should be taxed with lower tax rates. Then, it would be plausible to increase the dynamic of the economy. Also, the factories, the knowhow services of big companies, the health care system, and the educational system comprise a special case for the economy, as they belong to those cases where the taxes improve the quality of the economy. The factories and the big know-how companies increase the cycle of money, as they do

\footnotetext{
National Kapodistrian University of Athens (N.K.U.A.)
} 


\section{Articles}

not substitute the activities of the smallmedium companies and the freelancers. The educational and health care systems improve the quality of the economy, making the whole economy better (Challoumis, 2018). Therefore, this paper seeks to make clear how the concept of the cycle of money works in an actual case scenario like this of the economic system of Bulgaria. The index of the cycle of money suggests how an economic system ought to counteract a monetary crisis and examines how well-structured a country's economy is. The estimations of the index of the cycle of money of Bulgaria are used for a comparison with the global average index of the cycle of money. The results reveal that Bulgaria is close to the average global value and therefore could face an economic crisis, as it is a well-structured economy.

The concept of the cycle of money reveals that the taxes return to the economy, in the case of the education and the health care system (these are exclusions from the mainstream where taxes support the economy). But, the mainstream is that the tax authorities should maintain the taxes to the lowest level. For small and medium companies, the government should protect them with very low taxes and contemporaneously should put greater taxes on the larger companies. But, there is a type of big and international companies that should have low tax rates, as these types of companies do not substitute the activities of smaller companies. These types of big companies are factories and technological know-how companies. Then, the principal idea is to have a financial system, with the best allocation of production. (Helpman \& Krugman, 1989) Larger companies should not provide similar products and services, like that of smaller companies, as they can make investments in economic fields that smaller companies cannot support. In that way, an economic system achieves its best level. Additionally,
Index of the Cycle of Money - the Case of Bulgaria

the idea of the cycle of money shows that with the appropriate allocation of production units and of taxes the money is cycled inside the economy achieving the maximum dynamic of the economy. This paper is about Bulgaria's s index of the cycle of money. The research is based on an actual case scenario of a country's economic system. Therefore, the principal hypothesis of this paper aims to estimate the index of the cycle of money of Bulgaria and to answer the question if it's near the worldwide general index of the cycle of money, according to the simple index or the general index of the cycle of money. The cycle of money of Bulgaria should be similar or close to the worldwide general index of the cycle of money to be able to counteract a potential depression. The applied approach is based totally on mathematical estimations from the relevant theory. The results confirm that Bulgaria's economic system is properly established, as it follows the general international index of the cycle of money (the value of 0.5 ) which represents the average global case (Challoumis, 2018). The countries near 0.5 and above it have an appropriate distribution of money to their financial system. Consequently, Bulgaria's economic system is considered as well established, based on the results of this paper. The question about the way the index of the cycle of money works in the case of Bulgaria is answered from the structure of its economy and the way that the money is distributed to its economy. Besides, it needs some improvements to have an even better index cycle of money. Therefore, Bulgaria should decrease taxes for small and medium enterprises, to achieve better reuse of money in the country's economic system, and to increase taxes to big and international (OECD, July 2017). 


\section{Articles}

\section{LITERATURE REVIEW}

The case of Latvia presented the condition of the country's economy and how to react to an economic crisis, according to the index of the cycle of money. These results are based on the theoretical approach of the theory of the cycle of money, where this theory suggests that to an economy the taxes return to the society; basically this happens to the case of the education and the health system. But, the main rule is that the authorities should keep the taxes as low as is plausible, for the medium or small economic units (meaning any kind of economic unit e.g. freelancers), and companies (Challoumis, 2021).

The arm's length principle is the principle where the authorities apply the taxes to international and to groups of companies. The arm's length principle is the method that the tax authorities estimate the tax obligations of the companies which participate in international transactions (IMF, 2018).

For the authorities using the arm's length principle it is tough to obtain the controlled transactions, as the international companies offer similar data with that of the uncontrolled transactions and they hide with a purpose to avoid paying taxes. Therefore, the government needs to apply the fixed-length principle. The fixed-length principle indicates that the companies of controlled transactions manage transactions and achieve avoiding tax paying. Then, according to the fixed-length principle, international companies should pay plus a fixed amount of tax (IMF, et al., 2017). In that way, the cycle of money is enhanced, because the larger companies generally send the money out from the society and the economy and save them in international banks. Therefore, that money is lost from society, decreasing consumption (Challoumis, 2018). Then, according to the fixed-length principle, the local companies which save their money in local banks should have lower tax rates.

In conclusion, the fixed-length principle serves the theory of the cycle of money, where the small and medium companies pay lower taxes than the larger companies, which substitute their commercial activities. On the other hand, the arm's length principle estimates the taxes standing on methodologies provided by the companies that make international transactions. In that way, the large companies cover the activities of the smaller companies. Finally, the mainstream is that small and medium companies boost the distribution of money to a country's economy as usually they don't save their money out of the country's economic system, and reuse the money inside the economy. Therefore, the money distributed inside the economy increases the cycle of money many times. The reason why the money increases the cycle of money is obvious according to eq. (4) of the general index of the cycle of money.

A prior application of the theory of cycle money could be found in the case of Latvia, which belongs to the range of 0.5 meaning that is a well-structured economy and would not collapse to a strong economic crisis. In the case of Bulgaria the index of cycle of money is close to 0.5 , anticipating that Bulgaria could also face a strong economic crisis, but with a little bit slower rhythm. The countries that are above the value of 0.2 can counteract potential crises (Challoumis, 2020).

\section{METHODOLOGY}

The methodology applied for the current study is presented below, being in the same line with the presented theory. The calculations of the cycle of money are clarified by the following mathematical types:

$c_{y}=c_{m}-c_{\alpha}$ 


$$
\begin{aligned}
& c_{y}=\frac{d x_{m}}{d m}-\frac{d x_{m}}{d a} \\
& i_{c y}=Y * b_{d} \\
& g_{c y \text { Country }}=\frac{c_{y \text { coyntry's }}}{c_{y \text { Average }}+c_{y \text { coyntry's }}} \\
& g_{\text {cy Average }}=\frac{c_{y \text { Average }}}{c_{y \text { Averaqe }}+c_{y \text { Averaqe }}}=0.5
\end{aligned}
$$

The $c_{m}$ is the velocity of financial liquidity, $c_{a}$ is the velocity of escaped savings and $c_{y}$ is the cycle of money. The $i_{c y}$ is the index of the cycle of money, $Y$ is the national income or GDP, and $b_{d}$ is the bank deposits of the country. Moreover, $g_{c y}$ country symbolizes the general index of $c_{y}$ of the country, $c_{y}$ country's is the index of $c_{y}$ of the country, and $c_{y}$ Average is the global index of $c_{y}$. Finally, $g_{c y}$ Average is the general global index of $c_{y}$, and is obtained as a global constant.

Therefore, the main hypothesis is to establish the connection between the index of global average $c_{y}$, and the bank deposits and the GDP per capita, with an econometric approach. Then the initial hypothesis that the cycle of money of
Bulgaria is close to the global average index of the cycle of money is confirmed.

The eq. (4) and (5) mean that an economy close to the value of 0.5 can face an economic crisis. Results close to this value represent an appropriate index of the cycle of money, revealing an adequate economic structure of the society and then the fine distribution of money between the citizens - consumers.

\section{RESULTS - THE CASE OF BULGARIA}

Standing on the prior methodology the following results were extracted. This table includes the parameters of bank deposits, GDPs, and the indexes of the cycle of money. This section reveals the dependence of Bulgaria's index of the cycle of money using the bank deposits of Bulgaria's economy and the GDP per capita of Bulgaria's economy. The bank deposits of the global average case and the global GDP per capita are used for the comparison of Bulgaria's economy, in terms of its GDP, and the country's bank deposits.

The same conclusions arise from an econometric point of view also, with the dependent variable to be the index of the cycle of money:

Table 1: Bulgaria's regression analysis (Source: author's compilation)

\begin{tabular}{|l|r|r|r|}
\hline \multicolumn{1}{|c|}{ Variable } & \multicolumn{1}{c|}{ Coefficient } & \multicolumn{1}{c|}{ std. error } & \multicolumn{1}{c|}{ p-value } \\
\hline Constant & -497891 & 3300.00 & $4.39 \mathrm{e}-05$ \\
\hline Bulgaria's bank deposits & 7450.83 & 56.5297 & $5.76 \mathrm{e}-05$ \\
\hline Bulgaria's GDP per capita & 67.5729 & 0.241429 & $1.28 \mathrm{e}-05$ \\
\hline Global index of the cycle of money & -0.00602068 & 0.00497239 & 0.3496 \\
\hline
\end{tabular}

In the prior table, the values with two asterisks symbolize the cases where the coefficients are below the 0.05 significant level, and accordingly the three asterisks the case of 0.01 significant level.

The indexes reveal Bulgaria's distribution of money and the form of its economic structure (see Table 2). The first three rows of the table reveal that the $p$-value is important, therefore the initial hypothesis was rejected and the model is accurate. The fourth row is expected to be above the $0.1 \mathrm{p}$-value as the global index of the cycle of money is independent of any country's rate, as in most 


\section{Articles}

cases, a country has a very small amount to the aggregate value. Based on those estimations and the theoretical background the condition of the economic structure of the country is determined and if Bulgaria belongs to the good economies. According to these results, it's plausible to clarify the condition of the cycle of money in Bulgaria:

Table 2: Bulgaria's index of the cycle of money

(Source: Globaleconomy.com and author's compilation)

\begin{tabular}{|c|c|c|c|c|c|c|}
\hline Year & $\begin{array}{c}\text { Bank Deposits } \\
\text { Global } \\
\text { Average (\%) }\end{array}$ & $\begin{array}{c}\text { Bank Deposits } \\
\text { Bulgaria (\%) }\end{array}$ & $\begin{array}{c}\text { Global GDP } \\
\text { per Capita (\$) }\end{array}$ & $\begin{array}{l}\text { Bulgaria GDP } \\
\text { per Capita (\$) }\end{array}$ & $\begin{array}{c}\text { Index of } \\
\text { Global } \\
\text { Average Cy } \\
\text { (\$) }\end{array}$ & $\begin{array}{c}\text { Index of } \\
\text { Bulgaria's } \\
\text { Cy (\$) }\end{array}$ \\
\hline 2012 & 52.48 & 61.04 & $16,653.01$ & $7,393.19$ & $873,949.96$ & $451,280.32$ \\
\hline 2013 & 53.96 & 66.12 & $17,266.62$ & $7,651.18$ & $931,706.82$ & $505,896.02$ \\
\hline 2014 & 55.81 & 67.5 & $17,159.02$ & $7,874.18$ & $957,644.91$ & $531,507.15$ \\
\hline 2015 & 59.38 & 67.21 & $15,295.71$ & $7,053.16$ & $908,259.26$ & $474,042.88$ \\
\hline 2016 & 60.77 & 67.57 & $15,330.03$ & $7,545.79$ & $931,605.92$ & $509,869.03$ \\
\hline 2017 & 60.07 & 67.72 & $15,082.49$ & $8,331.06$ & $906,005.17$ & $564,179.38$ \\
\hline RESULTS & & & & & $5,509,172.04$ & $3,036,774.79$ \\
\hline
\end{tabular}

Bulgaria's bank deposits:

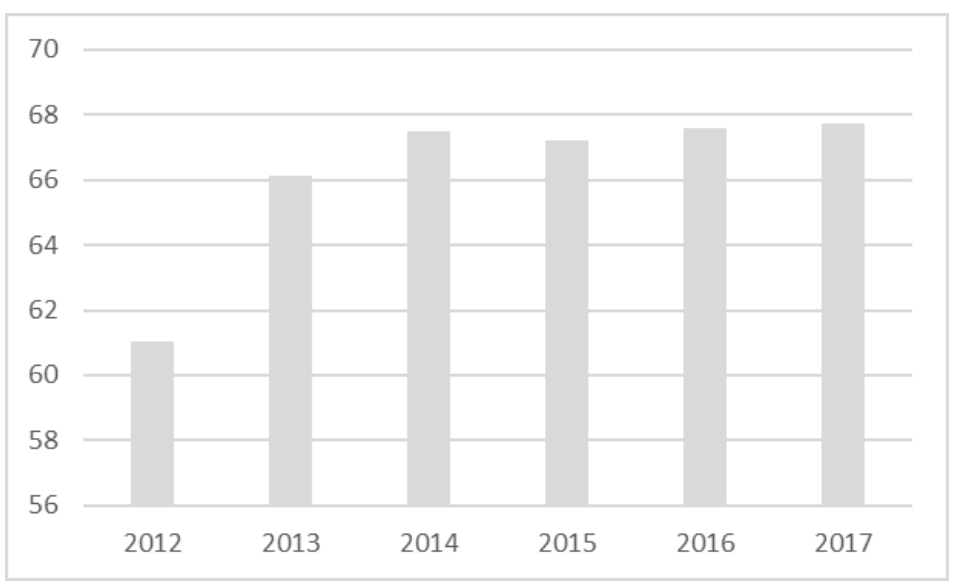

Figure 1. Bulgaria's bank deposits (Source: Globaleconomy.com)

Figure 1 presents the situation of bank deposits of Bulgaria's financial system, as a percent of the GDP, for the period from 2012 the GDPs of Bulgaria: 


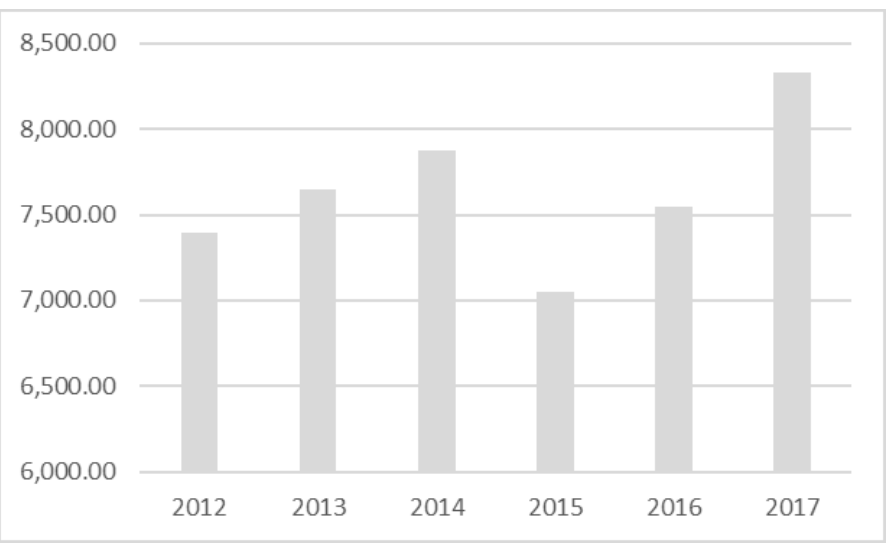

Figure 2: Bulgaria's GDPs per capita (Source: Globaleconomy.com)

Figure 1 presents the condition of GDPs of Bulgaria's economy for the period from 2012 to 2017. Also, the next scheme presents the GDPs of Bulgaria, for the same period.

According to prior results, the index of Bulgaria's $c_{y}$ is $3,036,774.79 \$$

We obtain from the prior results that:

The index of global average $c_{y}$ is $5,509,172.04$ \$

Calculating the general index of the cycle of money for the case of Bulgaria and of global view we arrive at:
- The general index of $c_{y}$ for Bulgaria is $g_{c y}$ Country $=0.355$

- The general index of $c_{y}$ of global view is $g_{c y \text { Average }}=0.5$

Therefore, it is concluded that Bulgaria's index cycle of money is close to the global average cycle of money. Then, the dynamic of Bulgaria's economy complies with the global average and its structure is near to the initial hypothesis. Then we receive the next scheme:

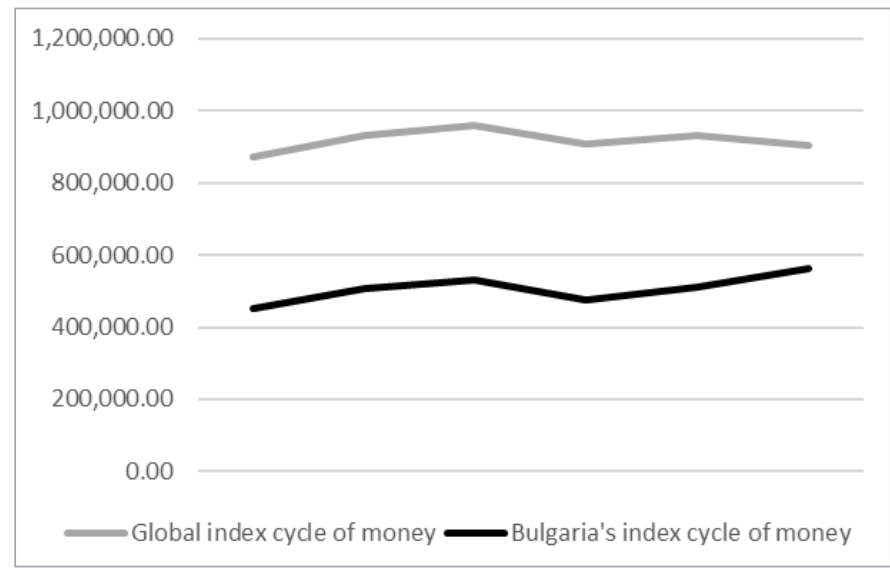

Figure 3: Graph of the index of the cycle of money (Source: author's compilation)

Based on the prior scheme, the conclusion is made that the index of the cycle of money of Bulgaria's economy is under but close to the global average of the index of the cycle of money, which is 0.5 (considered as a global constant). Bulgaria's index of the cycle of 


\section{Articles}

money is 0.355 . The countries that are near 0.5 have a well-structured economy - standing on eq. (5), according to the theoretical background of the cycle of money. This conclusion means that the economic structure of Bulgaria has a moderate distribution of money to its economy, then international transactions are not fully do not use the local banking system. Also, the international and the bigger companies substitute the local medium and small enterprises. Besides, the government should protect more the small and medium enterprises to avoid losing money from transactions of bigger companies. The authorities should apply the fixed-length principle, then higher taxes should be put on the bigger companies. In that way, the distribution of money inside the economy will be increased, and the social welfare will be boosted.

The general index of the cycle of money appears to the following figure:

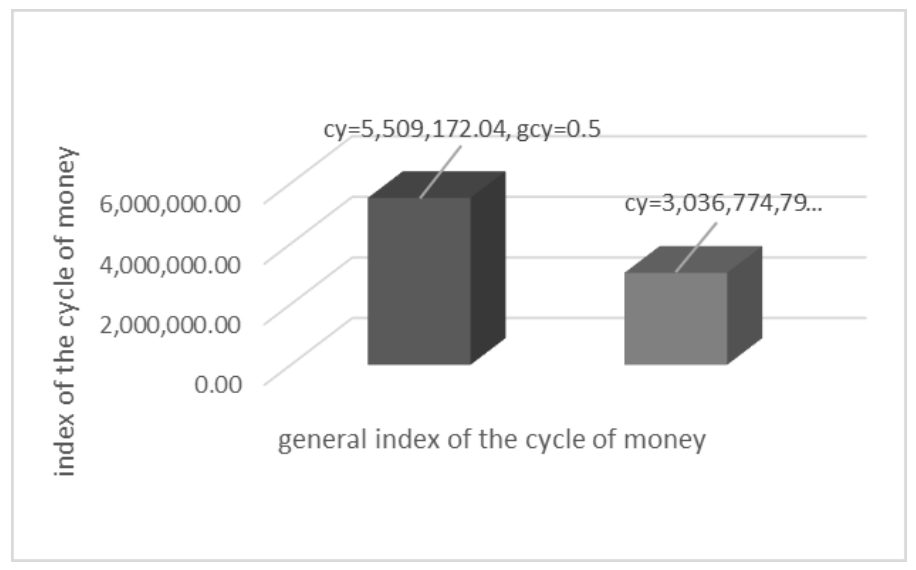

Figure 4: The cycle of money indexes (Source: author's compilation)

The prior scheme presents the combination of the index of the cycle of money with the case of the general index of the cycle of money. The affiliation between the global average indexes and Bulgaria's index is represented. Bulgaria is part of the countries which are close to the global average index of the cycle of money, both for the simple index and general index.

\section{DISCUSSION}

The interpretation is that this financial system belongs to the medium level of the cycle of money, then there is a medium dynamic, because the structure of the economy may be improved, with decreasing taxes to the small and the medium companies, and increase of taxes to the bigger companies. Moreover, the bigger companies have to provide economic activities that smaller businesses can't support, then the authorities ought to imply low taxes to know-how companies and factories. Therefore, large companies must no longer replace smaller businesses' activities. The investments of a country are boosted by the increase in the distribution of money. A country with a well-based economic system is a country with a good cycle of money and therefore it can face an economic crisis. Bulgaria's economic system is under, but near the index of common GDP per capita, from 2012 to 2017 using the index of average GDP per capita. Therefore, the question arises if the authorities can proceed to more structural changes to the economy, to achieve even 


\section{Articles}

better results, following the concept of the cycle of money.

\section{CONCLUDING REMARKS}

Based on the outcomes of the table, Bulgaria may be under, but near the worldwide average index of the cycle of money. Using figure 2 and figure 3 the index of the cycle of money is close to the worldwide average of the index of the cycle of money, displaying that Bulgaria's distribution of money is to a medium rate. The cycle of money of the country permits a good distribution of money. The losses of the local banks are to a moderate degree due to the fact that an amount of money is excluded from the local financial system by worldwide transactions (see table 2). The current model complies with the initial assumption, showing the distribution of money to Bulgaria's economy. Bulgaria's economic system has a tendency in the last years to have better reuse of money within the financial system than in the past, as it tends to have closer characteristics to a financial system that complies better with the idea of the cycle of money. Finally, Bulgaria's financial dynamic is close to the worldwide average cycle of money.

\section{REFERENCES}

Argyris, C. \& Schon, D., 1974. Theory in Practice. San Francisco: Jossey - Bass.

Ariely, D., Loewenstein, G. \& Prelee, D., 2003. Coherent arbitrariness: Stable demand curves without stable preferences. Quarterly Journal of Economics, pp. 73-105.

Bank de France, 2018. Costs and consequences of a trade war: A structural analysis. Policy paper.

Boland, L. A., 1991. The Methodology of Economic Model Building. London and New York: Routledge.
Index of the Cycle of Money - the Case of Bulgaria

Camerer, C. F., 2003. The behavioral challenge to economics: Understanding normal people. Federal Reserve of Boston meeting "How Humans Behave". Caltech, Pasadena CA 91125, pp. 1-34.

Challoumis, C., 2017. Quantification of Everything (A Methodology for Quantification of Quality Data with Application and to Social and Theoretical Sciences). SSRN.

Challoumis, C., 2018. The arm's length principle and the fixed length principle economic analysis. [Online] Available at: http://www.worldscientificnews. com/wp-content/uploads/2018/11/WSN115-2019-207-217.pdf

Challoumis, C., 2018. The Theory of Cycle of Money. SSRN, p. https://ssrn.com/ abstract=3149156 or http://dx.doi.org/10.2139/ ssrn.3149156.

Challoumis, C., 2019. Theoretical analysis of fuzzy logic and $Q$. E. method in economics. IKBFU 's Vestnik, pp. 59 - 68.

Challoumis, C., 2020. Index of the Cycle of Money - The case of Latvia. Economics and Culture, 17(2).

Challoumis, C., 2020. Analysis of the theory of cycle of money. Acta Universitatis Bohemiae Meridionalis, 23(2), 13 - 29.

Challoumis, C. K., 2018. Methods of Controlled Transactions and the Behavior of Companies According to the Public and Tax Policy. ECONOMICS, De Gruyter, Sciendo, 6(1) (ECONOMICS, 6(1), 33-43. DOI: https://doi. org/10.2478/eoik-2018-0003), pp. 33-43.

Challoumis, C. K., 2018. Multiple Axiomatics Method Through the Q.E. Methodology. SSRN.

Challoumis, C. K., 2018. The impact factor of health on the economy using the cycle of money. Bulletin of the Transilvania University of Brasov, Series V: Economic Sciences Vol. 11 (60) No. 1 - 2018. 
Challoumis, C. K., 2018. The Keynesian Theory and the Theory of Cycle of Money. Hyperion, p. https://hej.hyperion.ro/ articles/3(6)_2018/HEJ\%20nr3(6)_2018_ A1Challoumis.pdf.

Challoumis, C. K., 2019. The R.B.Q. (Rational, Behavioral and Quantified) Model. [Online] Available at: https://doi.org/10.15388/ ekon.2019.1.1

Challoumis, C. K., 2019. Transfer Pricing Methods for Services and the Policy of Fixed Length Principle. Economics and Business, 33(1), pp. 222-232.

Challoumis, C. K., 2020. The Impact Factor of Education on the Public Sector - The Case of the U.S. IJBESAR, 13(1), pp. 69-78.

Challoumis, C. K., Years XXIII. The Role of Risk to the International Controlled Transactions. Annals of "Dunarea de Jos" University of Galati, no2/2018(ISSN-Online 2344-441X).

De Nederlandsche Bank, 2018. Economic Developments and Outlook. Report 15.

Education, U. D. o., 2020. [Online] Available at: Data: https://www2.ed.gov/about/ overview/budget/history/index.html

Erceg, C., Prestipino, A. \& Raffo, A., 2018. The macroeconomic effects of trade policy. International Finance Discussion papers 1242.

Feinschreiber, R., 2004. Transfer pricing Methods An Application Guide. new Jersey: John Wiley\&Sons.

Foundation for Economic and Industrial Research, 2019. Education in US: Crisis and Development of Public and Private Expenditures, FEIR, p.83. [Online] Available at: http://iobe.gr/docs/research/ RES_05_F_14032019_REP.pdf

Gihman, I. \& Skorohod, A. V., 1972. Stochastic Differential Equations. Springer-Vertang Inc. New York.
Gihman, I. \& Skorohod, A. V., 1974. The theory of Stochastic Possesses. Springer-Vertang Inc. New York.

Gomes-Casseres, B., 1989. Ownership Structures of Foreign Subsidiaries: Theory and Evidence. Journal of Economic Behavior and Organization, pp. 1 - 25.

Goodman, N., 1978. Ways of Worldmaking. Indianapolis: Hackett.

Gordon, L., 1976. Survey of Interpersonal Values - Revised Manual. Chicago: Science Research Associates.

Habermas, J., 1968. Knowledge and Human Interests. Boston: Beacon Press.

Helpman, E. \& Krugman, P., 1989. Trade Policy and Market Structure. MIT Press.

Horsten, L., 2017. Stanford Center for the Study of Language and Information. [Online] Available at: https://plato.stanford.edu/entries/ philosophy-mathematics/

IMF, 2018. World Economic Outlook.Report.

IMF, World Bank \& WTO, 2017. Making trade an engine of growth for all. Policy Paper. s.l.:s.n.

King, E., 2009. Transfer pricing and corporate taxation problems, Practical Implications and Proposed Solutions. Springer.

Lerner, A., 1936. The symmetry between export and import taxes. Economica, Issue 3 , pp. 306-313.

Linde, J. \& Pescatori, A., 2017. The macroeconomic effects of trade tariffs: Revisiting. CEPR Discussion Papers 12534.

McKay, A., Nakamura, E. \& Steinsson, J., 2016. The power of forward guidance revisited. American Economic Review.

Meier, B. D. \& Rosenbaum, D. T., 2000. Making single mothers work: Recent tax and welfare policy and its effects. Volume 53 (4). 
Mirman, L. J., 1971. Uncertainty and Optimal Consumption Decisions. Econometrica, Volume 39.

OECD, 2001. Transfer Pricing Guidelines for Multinational Enterprises and Tax Administrations. Paris: OECD.

OECD, 2010. Review of comparability and of profit methods: revision of Chapters-III of the Transfer Pricing Guidelines. s.I.:CTPA.

OECD, 2018. Trade policy and the global economy - Scenario 2: Increasing tariffs.

OECD, 2019. Gross domestic product (GDP) (indicator).

OECD, 2020. Trend. [Online] Available at: https://www.oecd-ilibrary.org/ docserver/eag_highlights-2012-15-en.pdf?exp ires $=1556715212 \& i d=i d \& a c c n a m e=$ guest $\&$ ch ecksum=0EFAA6AF2172417614D9616D1DB3 10C8, https://doi.org/10.1787/eag_highlights2012-15-en
OECD, July 2017. Transfer Pricing Guidelines for Multinational Enterprises and Tax Administrations. Paris: OECD Publishing.

Ossa, R., 2014. Trade wars and trade talks with data. American Economic Review, 104(12), pp. 4104-46.

Timothy, R. J., 2010. Fuzzy Logic with Engineering Applications. Wiley.

United Nations, 2013. Practical Manual on Transfer Pricing for Developing countries. New York: United Nations Department of Economic \& Social Affairs.

Van Wijnbergen, S., 1987. Tariffs, employment and the current account: Real wage resistance and the macroeconomics of protectionism.. 28(3), pp. 691-706.

Wilson, J. D., 1986. A theory of interregional tax competition journal of Urban Economics. Volume 19 (3) pp.296-315. 